\title{
THIAMINE BIOSYNTHESIS IN BACTERIA
}

\author{
FUMITO SHIMOMURA, JUICHI OGATA, HIDEO NAKAYAMA \\ AND RYOJI HAYASHI
}

Deparment of Microbiology, Yamaguchi Medical School, Ube

(Received February 3, 1957)

Many bacteria are known to synthesize thiamine in the cells. It is generally believed (1-3) that the pathway of its biosynthesis is as follows: Pyrimidine moiety $(\mathrm{Pm})+$ thiazole moiety $(\mathrm{Th}) \longrightarrow$ thiamine $\longrightarrow$ thiamine pyrophospate. The results of the experiments concerning the matter performed by the authors are presented here.

\section{THIAMINE BIOSYNTHESIS BY WASHED STAPHYLOCOCCI}

It is well known that Staphylococcus aureus requires thiamine for growth and the requirement for the vitamin is met by $\mathrm{Pm}$ plus Th. Thiamine is also known to be synthesized from $\mathrm{Pm}$ and $\mathrm{Th}$ by the coccus (4-7).

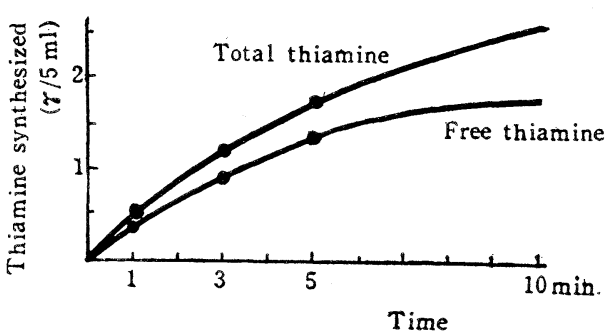

Frg. 1 Thiamine Synthesis of Staph. aureus FAD $209 P$

Reaction system : Washed cells cultured for 14 hours $(50 \mathrm{mg} / \mathrm{ml}) 1 \mathrm{ml}, M / 15$ phosphate buffer ( $\mathrm{pH} 6.5) 1 \mathrm{ml}, 10^{-3} M$ Pm $0.5 \mathrm{ml}$, $10^{-3} M$ Th $0.5 \mathrm{ml}$, water $2 \mathrm{ml}, 30^{\circ}$.

If $\mathrm{Pm}$ and $\mathrm{Th}$ are added to a suspension of washed cells from a young culture of Staphylococcus aureus, thiamine is rapidly synthesized and thiamine pyrophosphate also increases (Fig. 1). Since this reaction takes place without a lag phase, it is presumed that the reaction is catalyzed by the enzyme preexisting in the cells. Therefore the reaction system $\longrightarrow \mathrm{Pm}+\mathrm{Th} \longrightarrow$ thiamine $\longrightarrow$ thiamine pyrophosphate — is presumed to be present as a normal pathway in the staphylococcus. On the other hand, the washed cells also break

TABLE I

Thiamine Decomposition by Staph. aureus FAD $209 P$

Reaction system : Washed cells cultured for 15 hours $(50 \mathrm{mg} / \mathrm{ml}) 1 \mathrm{ml}, M / 15$ phosphate buffer $(\mathrm{pH}, 6.5) 1 \mathrm{ml}$, thiamine $(3 \gamma / \mathrm{ml}) 1 \mathrm{ml}$, water $2 \mathrm{ml}, 40^{\circ}$.

\begin{tabular}{c|rcccccccc}
\hline Reaction time & 0 & $15 \mathrm{sec}$ & $30 \mathrm{sec}$ & $1 \mathrm{~min}$ & 3 & $\mathrm{~min}$ & $10 \mathrm{~min}$ & $30 \mathrm{~min}$ & $1 \mathrm{hr}$ \\
\hline $\begin{array}{c}\text { Residual thiamine } \\
(\%)\end{array}$ & 100 & 96 & 90 & 88 & 85 & 62 & 54 & 22 \\
\hline
\end{tabular}


down thiamine to $\mathrm{Pm}$ and $\mathrm{Th}$ as shown in Table I, whereby no lag phase is detected. Therefore, the reaction system - thiamine $\longrightarrow \mathrm{Pm}+\mathrm{Th} \longrightarrow$ is also presumed to be present as a normal metabolic pathway of the coccus.

Factors which definitely effect the reaction of the coccus - $\mathrm{Pm}+$ $\mathrm{Th} \rightleftharpoons$ thiamine $\longrightarrow$ thiamine pyrophosphate-are the presence of oxygen and the adsorption of the substrates (thiamine, Pm, Th) on the cells. When the bacterial suspension is added to the substrate solution, the substrate is adsorbed on the cells (Fig. 2) forming a layer of highly concentrated substrate on the surface of the cells, whereby the concentration of the substrate in the solution decreases. Therefore, if the bacterial suspension is centrifuged after adding the substrate, and the substrate concentration of the supernatant is measured, the amount adsorbed can be determined. This amount is, in reality, a sum of the amount adsorbed and that absorbed into the cells but it is clear that both contribute

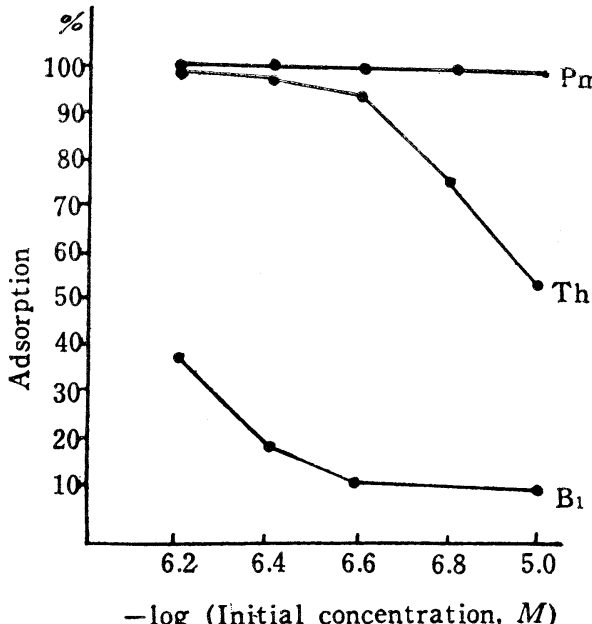

Fig. 2 Adsorption of Thiamine, Pm and Th by Staph. aureus FAD $209 \mathrm{P}$

Reaction system: Washed 15 hours incubated cells $(50 \mathrm{mg} / 5 \mathrm{ml}), \mathrm{pH} 6.5,30^{\circ}, 2$ minutes. to the progression of the reaction - $\mathrm{Pm}+\mathrm{Th} \rightleftharpoons$ thiamine. Shaking, aeration or addition of $\mathrm{H}_{2} \mathrm{O}_{2}$ to the system results in an increase in the amounts of thiamine and its ester synthesized. Since these procedures increase the amounts of substrates adsorbed (or absorbed), the thiamine synthesis is also

TABLE II

Synthesis and Degradation of Thiamine by Staph. aureus FAD $209 P$

(A) Synthesis (thiamine $r / 5 \mathrm{ml}$ )

Reaction system : Washed cells cultured for 14 hours $(50 \mathrm{mg} / \mathrm{ml}) 1 \mathrm{ml}$, $M / 15$ phosphate buffer (pH 6.5) $1 \mathrm{ml}, 10^{-4} M \mathrm{Pm} 0.5 \mathrm{ml}, 10^{-4} M \mathrm{Th}$ $0.5 \mathrm{ml}$, water $2 \mathrm{ml}, 30^{\circ}$.

\begin{tabular}{|c|c|c|c|c|c|c|}
\hline \multirow{3}{*}{ Reaction time } & \multicolumn{3}{|c|}{ Stationary } & \multicolumn{3}{|c|}{ Aerated } \\
\hline & \multicolumn{2}{|c|}{ In cells } & \multirow{2}{*}{$\frac{\text { In supernatant }}{\text { Total }}$} & \multicolumn{2}{|c|}{ In ceils } & \multirow{2}{*}{$\begin{array}{c}\text { In supernatant } \\
\text { Total }\end{array}$} \\
\hline & Free & Total & & Free & Total & \\
\hline$h r$ & & & & & & \\
\hline 0 & 0 & 0.1 & 0 & 0 & 0.1 & 0 \\
\hline 1 & 2.46 & 3.13 & 0.27 & 2.63 & 4.63 & 0.7 \\
\hline 2 & 1.47 & 2.57 & 1.73 & 2.87 & 6.80 & 0.53 \\
\hline 3 & 0.67 & 1.27 & 1.73 & 0.9 & 4.83 & 0.3 \\
\hline
\end{tabular}


(B) Degradation (thiamine $\boldsymbol{\gamma} / 5 \mathrm{~m} 1$ )

Reaction system : Washed cells cultured for 14 hours $(50 \mathrm{mg} / \mathrm{ml}) 1 \mathrm{ml}$, $M / 15$ phosphate buffer $(\mathrm{pH} 6.5) 1 \mathrm{ml}, 10^{-4} M$ thiamine $0.5 \mathrm{ml}$, water $2.5 \mathrm{ml}, 30^{\circ}$.

\begin{tabular}{c|cc|c|cc|c}
\hline \multirow{2}{*}{ Reaction time } & \multicolumn{4}{|c|}{ Stationary } & \multicolumn{3}{c}{ Aerated } \\
\cline { 2 - 7 } & \multicolumn{2}{|c|}{ In cells } & In supernatant & \multicolumn{2}{c|}{ In cells } & In supernatant \\
\cline { 2 - 7 } & Free & Total & Total & Free & Total & Total \\
\hline$h r$ & & & & & & \\
0 & 0 & 0.2 & 17.0 & 0 & 0.2 & 17.0 \\
1 & 1.87 & 2.55 & 11.9 & 2.4 & 5.32 & 1.1 \\
2 & 1.36 & 2.69 & 10.71 & 2.17 & 6.78 & 0.5 \\
3 & 1.36 & 2.53 & 9.86 & 2.66 & 4.93 & 0.67 \\
\hline
\end{tabular}

promoted. The absorption of thiamine by yeast is reported to be intensified by the presence of an energy-rich substrate or by an aeration in the presence of an energy-rich substrate (8). A similar mechanism may presumably exist in the case of adsorption by the staphylocci. The thiamine phosporylation in the retina is reported to be conjugated with the respiration energy of $\mathrm{C}_{4^{-}}$dicarboxylic acid (9). The acceleration of thiamine phosphorylation by

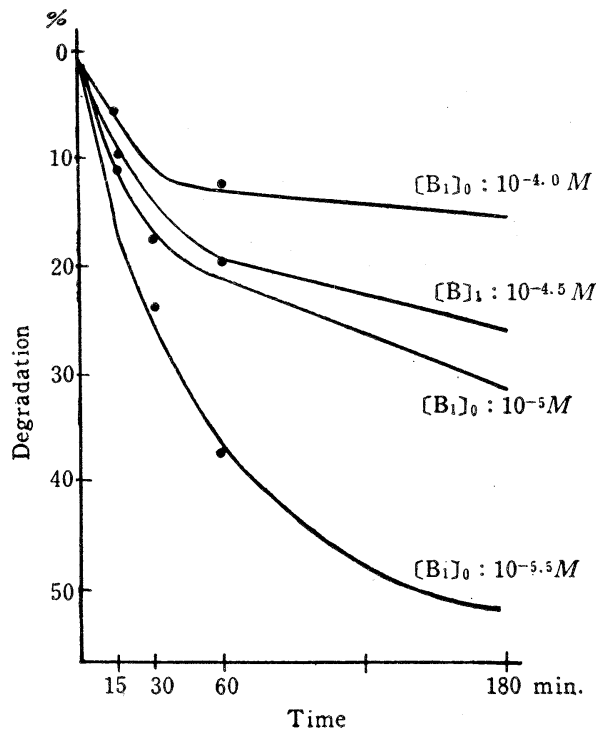

FIg. 3 Thiamine Degradation by CellFree Extract of Staph. aureus FAD $209 P$ Reaction system : Cell-free extract $(0.46$ $\mathrm{mg} \mathrm{N} / \mathrm{ml}) 1 \mathrm{ml}, M / 15$ phosphate buffer (pH 6.5) $1 \mathrm{ml}$, thiamine solution $1 \mathrm{ml}, 30^{\circ}$. $\left[\mathrm{B}_{1}\right]_{0}$ : Initial thiamine concentration aeration of this bacteria may be related to this. Table II shows the results of the experiment, in which synthesis $(\mathrm{Pm}+\mathrm{Th} \longrightarrow$ Thiamine) and degradation (thiamine $\longrightarrow \mathrm{Pm}+$ Th) are started with equal concentrations $\left(10^{-5} \mathrm{M}\right)$. In the degradation reaction (Table II-B) with thiamine as the substrate, there is a more rapid disappearance of the vitamin from the supernatant when aeration is performed than when left standing. It is not due to conversion of the vitamin to thiothiamine, thiazolone derivative or thiamine disulfide, presumably the amount of the vitamin adsorbed or absorbed is increased as a result of aeration and the vitamin adsorbed is further actively broken down.

A comparison of A (synthesis) and $B$ (degradation) of Table II shows that the intra- and extracellular thiamine in aeration and the intracellular thiamine in the stationary 
case reach roughly the same levels, suggesting that a balance is maintained between the reactions $(\mathrm{Pm}+\mathrm{Th} \rightleftharpoons$ thiamine $\rightleftharpoons$ ester $)$ according to the condition of the bacteria.

The extract prepared by destruction of the cells degrades thiamine as presented in Fig. 3. Since this degrading factor possesses the character of thiaminase II (23), the thiamine degradation by living cells is assumed to be due to thiaminase II. Thiaminase II may possibly also take part in the synthesis of thiamine, but this point is yet to be verified.

\section{THIAMINE BIOSYNTHESIS BY BACTERIAL AND FUNGAL MUTANTS}

Irradiation with ultra-violet or X-ray or treatment with nitrogen mustard or formaldehyde is known to increase the incidence of mutants of Escherichia coli and other bacteria with simple nutritional requirements. The auxotrophs thus obtained are used in studies on metabolism and heredity as well as for the assay of nutritional factors. Davis (10), Lederberg et al. (11-13) have simplified the isolation of mutants by the use of penicillin. The present authors have also succeeded by means of penicillin technique in isolating many mutants of $E$. coli requiring thiamine, $\mathrm{B}_{12}$, biotin, nicotinic acid, PABA, pantothenic acid, amino acids, etc.

1. The Pathway, Pm + Th $\longrightarrow$ Thiamine, in Escherichia coli

From the findings described below the course, $\mathrm{Pm}+\mathrm{Th} \longrightarrow$ thiamine, is assumed to be the main pathway in the biosynthesis of thiamine in $E$. coli.

(a) The thiamine content (mostly esterified) of E. coli ATCC 9637 (wild strain) cultured on the synthetic agar medium of Davis and Mingioli (16) containing both $\mathrm{Pm}$ and $\mathrm{Th}$ is definitely greater than that of the cells cultured in the medium devoid of both $\mathrm{Pm}$ and Th. (Fig. 4). The reaction, $\mathrm{Pm}+\mathrm{Th}$ $\longrightarrow$ thiamine, therefore is assumed to take place in the bacilli.
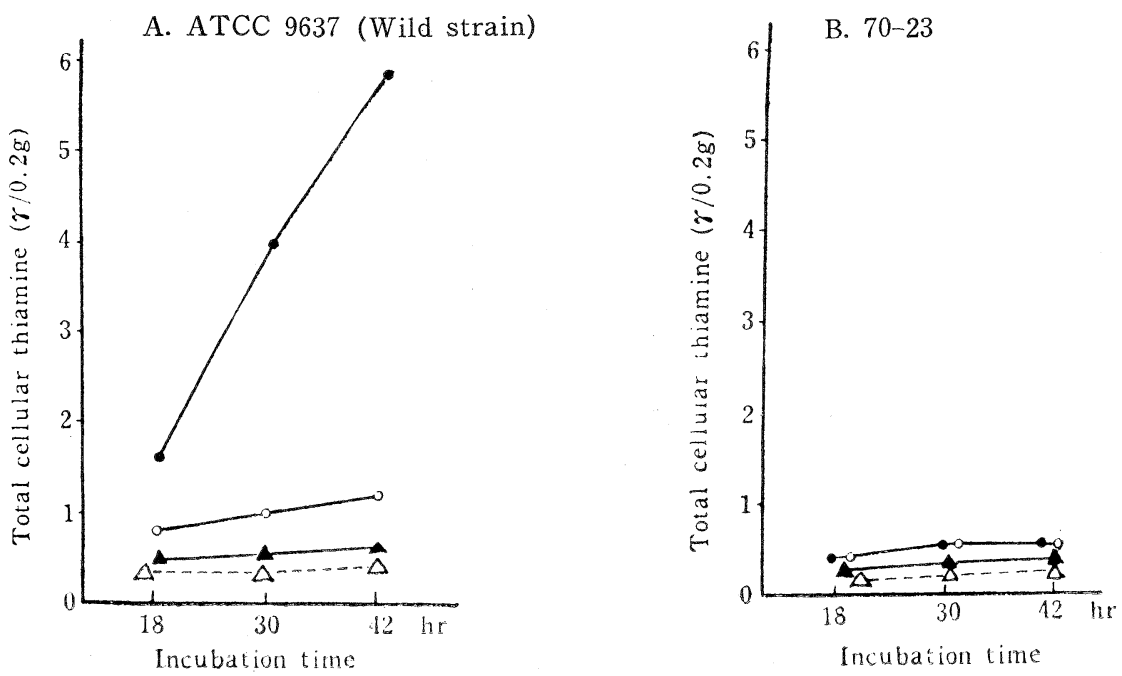

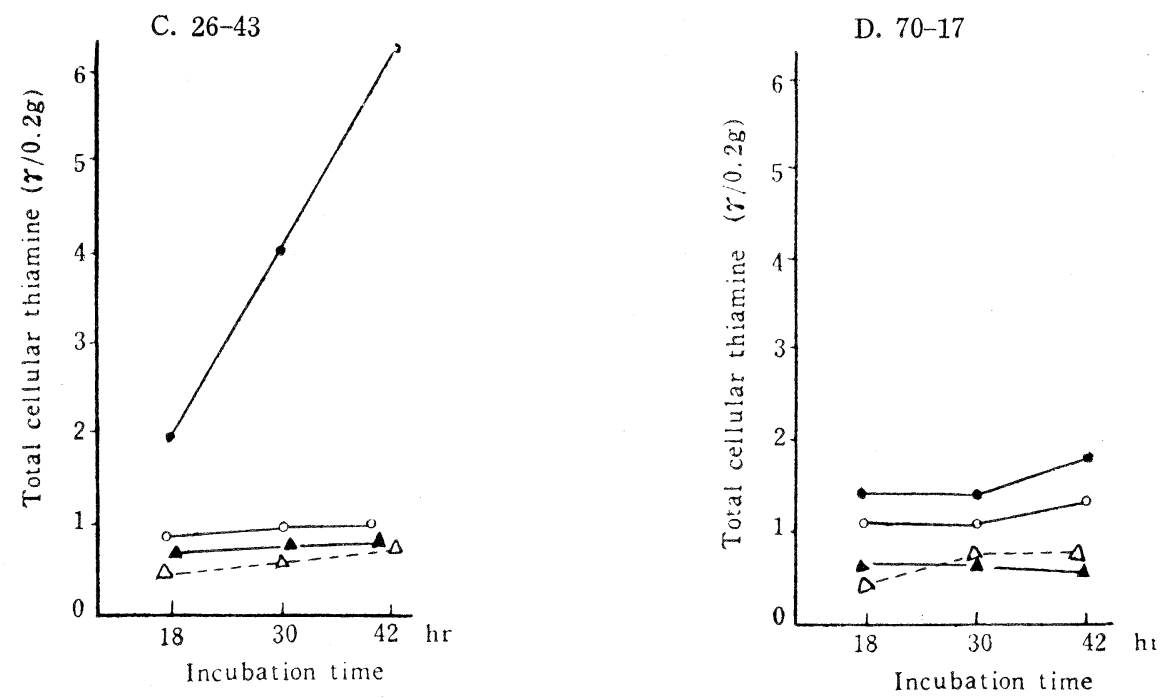

FIG. 4 Thiamine Synthesis by E. coil

Basal medium : Davis-Mingioli synthetic agar medium.

Concentration of $\mathrm{Pm}$ or $\mathrm{Th}, 2 \times 10^{-4} \mathrm{M}$.

- $\mathrm{Pm}+\mathrm{Th}, \quad \bigcirc \mathrm{Pm}, \quad \Delta \mathrm{Th}, \triangle$ Basal medium.<smiles>CC1N=C(N)SC1CCO</smiles>

(c) E. coli mutant 70-23 (Davis) proliferates in 24 hours of incubation in the presence of thiamine, but $\mathrm{Pm}$ and $\mathrm{Th}$, singly or in combination, have no effect (Fig. 6-A).

That there is no inhibition of thiamine utilization in this strain is suggested by the equivalency of the vitamin to this mutant and two other thiaminerequiring mutants derived from the same parent organism (ATCC 9637) (Fig. $6-\mathrm{A}, \mathrm{C}, \mathrm{D})$. With mutant 70-23, synthesis of thiamine does not occur from a combination of $\mathrm{Pm}$ and $\mathrm{Th}$ in a medium containing a minute quantity of thiamine (Fig. 4, B). It can therefore be assumed that the pathway, Pm + $\mathrm{Th} \longrightarrow$ thiamine, is blocked in this strain.

(d) E. coli mutant 8 multiplies in the presence of thiamine or $\mathrm{Pm}$ but fails to grow with Th alone (Fig. 6-B). E. coli mutant 26-43 (Davis) multiplies in the presence of thiamine or $\mathrm{Th}$, but fails to grow with $\mathrm{Pm}$ alone (Fig. 6-D). Strain 8 has reverted to the prototroph and could not be studied in detail. Presumably the pathway of $\mathrm{Pm}$ synthesis was disturbed in this strain. In 26-43 strain, the ability to synthesize thiamine from a 
combination of $\mathrm{Pm}$ and $\mathrm{Th}$ is the same as the parent strain (Fig. 4, C). The pathway of Th synthesis from a Th precursor is therefore disturbed rather than the pathway, $\mathrm{Pm}+\mathrm{Th}$ $\rightarrow$ thiamine. That thiamine and Th are equally active in the growth of this strain (Fig. 6-D), is consistent with the assumption that Th exists in the chief pathway of thiamine synthesis.

(e) Mutants which multiply in the presence of either thiamine, Pm or Th alone, as E. coli mutant $70-17$ (Davis), are also found (Fig. 6, C). In this strain, thiamine synthesis is weaker than that in the parent strain (Fig. 4, D), suggesting the partial block in the pathway, $\mathrm{Pm}+\mathrm{Th} \longrightarrow$ thiamine.

2. Pathway of the Formation of $\mathrm{Pm}$ and Th in Escherichia coli and Neurospora crassa

Synthesis of Pm Takata and Fukui (15) have studied the precursor of Pm using Mucor racemosus and found yeast nucleic acid to be available for the synthesis of thiamine. A combination of thymine and uracil are also found by the authors to permit the growth of $E$. coli mutant $70-17$. Pm is therefore assumed to be related to the pyrimidine of nucleic acid in E. coli.

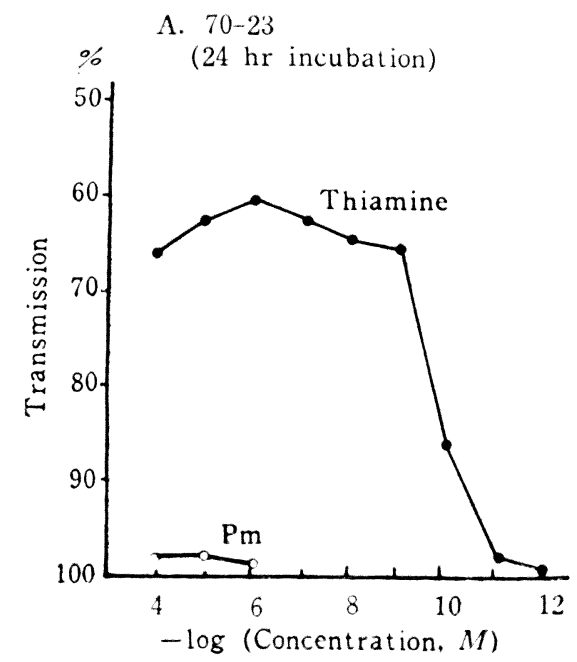

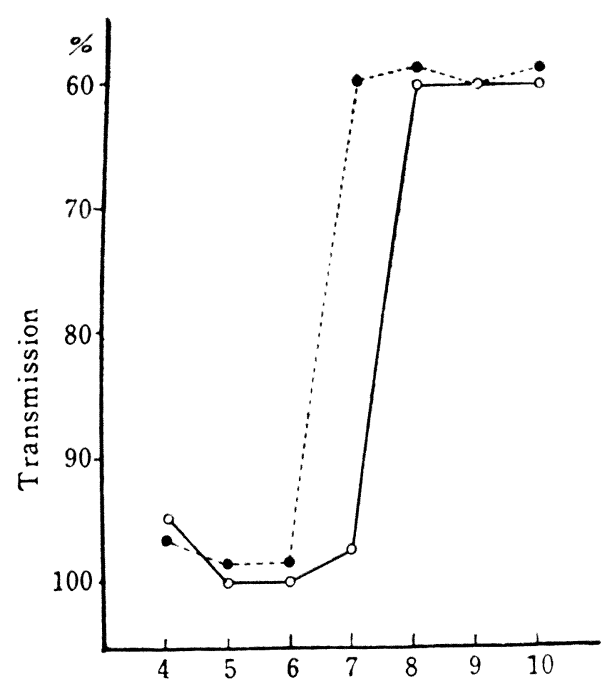

- $\log$ (Concentration of Am-Th, M)

Fic. 5 Inhibition by Amino-Th on the Cirowth of E. coli ATC C 96.37

(36 hr incucation)

- Minimal medium $+10^{-9} M \mathrm{Th}$

Minimal medium 
C. $70-17$

(24 $\mathrm{hr}$ incubation)

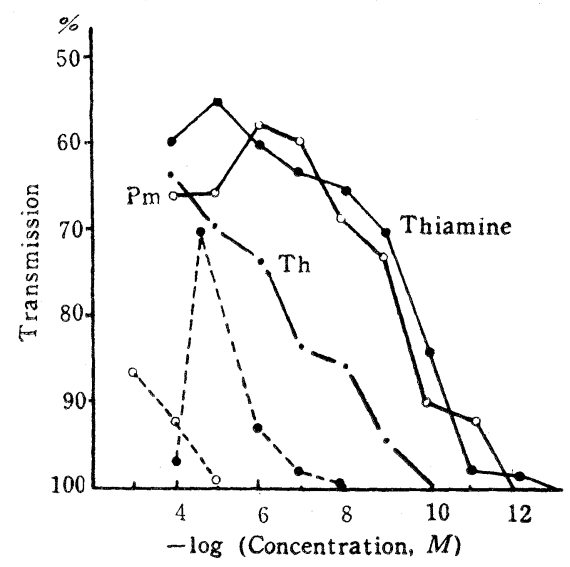

D. $26-43$

(24 $\mathrm{hr}$ incubation)

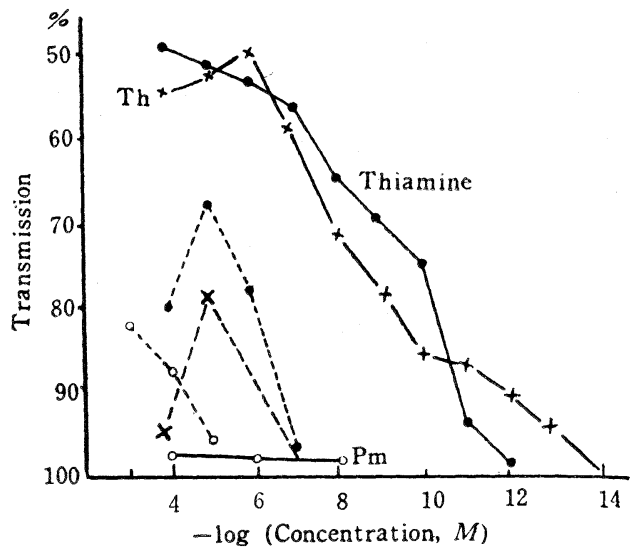

FIG. 6 Growth Curve of E. coli Mutant

Basal medium, Davis-Mingioli synthetic agar medium

- Th..... Thiazolidine carboxylic acid

$\bigcirc \cdots \cdots . . .0$ Cystine

$\times \cdots \cdots \times \gamma$-Aceto-mercaptopropyl acetate + J. P. formalin $\left(1: 10^{5}\right)$.

Synthesis of Th-Harington and Moggaridge (16) have suggested $\alpha$-amino$\beta$-(4-methylthiazole-5)-propionic acid (II) to be a precursor of Th. Yeast was reported to convert II to Th yielding about 60 per cent. Buchman et al. (1, 17) have presumed $\beta$-(4-methyl-thiazole-5)-alanine (III) to be the precursor of Th. III has been reported to convert to $\mathrm{Th}$ by pea root but not by Phy. comyces blakesleeanus (1) or Staph. aureus (1). Doudney and Wagner (18) have suggested the formation of III by condensation of formylated homocysteine metabolite with $\mathrm{C}_{2}$-amine in Neurospora. Bonner and Buchman (17) have reported the formation of Th from thioformamide and acetopropyl- or chloroacetopropyl-alcohol by pea root, but Tatum and Bell (19) have failed to detect the activities of these combinations in Neurospora crassa 18558 (Th-less) and<smiles>Cc1ncsc1C(N)C(=O)O</smiles>

II<smiles>CC1N=CSC1CC(N)C(=O)O</smiles>

III

assumed that neither combination is involved in the normal synthesis of Th by that fungus.

As stated above, Pm and Th are generally assumed to be formed separately and thiamine is synthesized by the combination of the two. This view has been verified by the authors in E. coli. Makino et al. (7) have reported 
thiamine synthesis from $5 \cdot \mathrm{CH}_{2} \cdot \mathrm{NH} \cdot \mathrm{CHS}-\mathrm{Pm}$ plus acetopropyl alcohol (pigeon) or chloroacetopropyl alcohol (Staphylococcus aureus), or $5-\mathrm{CH}_{2} \mathrm{NH}_{2}-\mathrm{Pm}$ plus methionol (pigeon, Staph. aureus) or methionine (Staph. aureus), or $5-\mathrm{CH}_{2} \mathrm{NH}_{2}$ Pm plus adenyl thiomethylpentose plus acetopropyl alcohol (Staph. aureus) and proposed the possibility of the formation of $\mathrm{Pm}$ followed by the secondary formation of Th. Matsukawa and Yurugi (20) also belived the secondary formation of Th. Takata and Fukui (21) reported thiamine synthesis from 5 - $\mathrm{CH}_{2} \mathrm{NHCHO}-\mathrm{Pm}$ plus $\gamma$-aceto- $\gamma$-chloropropyl alcohol in Mucor recemosus, Saccharomyces saké and Serratia marcescens. Matsukawa and Iwazu (22) observed the formation of dihydro-thiamine from $5-\mathrm{CH}_{2} \mathrm{NH}_{2}-\mathrm{Pm}$ plus $\mathrm{HCHO}$ plus $\gamma$-aceto- $\gamma$-mercaptopropyl alcohol and proposed the possibility of these substances to be the precursors of thiamine.

Accoring to Tatum and Bell (19), the thiamine-less mutants, N. crassa 17084 and $N$. sitophila 1090, both of which differed from normal by a single gene, required intact thiamine or a combination of $\mathrm{Pm}$ and $\mathrm{Th}$. Moreover, the cells of the two strains grown in the presence of a minute quantity of thiamine contained the active substances for both thiamine-less $N$. crassa 9185 and Th-less 18558. These substances were active neither for $N$. crassa 17084 nor N. sitophila 1090; therefore, they were thiamine-like substances rather than thiamine itself. Tatum et al., however, did not deny the assumption that Pm and Th are synthesized separately and thiamine is synthesized by a combination of the two in Neurospora, but presumed the strains 17084 and 1090 to be partially disturbed in the utilization of thiamine rather than in the synthesis of the vitamin.

\section{RESULTS OF THE AUTHORS' EXPERIMENTS}

\section{Effect of Cysteine, Cystine and Thiazolidine Carboxylic Acid}

The $E$. coli mutant capable of growing with Th grows also with a relatively large quantity of cystine (Fig. 6, C, D). Cysteine is also effective. Thiazolidine carboxylic acid (IV) synthesized from cysteine and formaldehyde is also effective in a lower concentration than cystine. The pathway, cystine (cysteine) $\longrightarrow$ IV $\longrightarrow$ Th, may therefore exist in E. coli, but whether this is the main pathway for $\mathrm{Th}$ synthesis is not clear. The mutants used for this experiment are assumed to differ in a single<smiles>CCCCCCCCSCC(CN)C(=O)O</smiles>

IV gene from normal and are therefore expected to be blocked in only one reaction involved in the biosynthesis of thiamine. Though the utilization of the same substance by a bacterium may differ according to whether it is supplemented from without or synthesized in the cell, and though a reaction involved in a biosynthesis may be partially blocked, a normal precursor is generally expected either to be completely inactive or to show activity of the same order of magnitude as the final product. Moreover, IV has not been detected in the parent strain cells.

$N$. crassa 18558 (Th-less) also behaves as E. coli. In the cells of this strain grown in the presence of IV both thiamine and Th could be detected. 


\section{Effect of Methionine, Methionol and Homocystine}

These substances proved to be entirely inactive for mutants of $E$. coli and $N$. crassa. From our experiments, it is not clear whether Th is synthesized from these amino acids. Neither these amino acids showed any beneficial effect on the thiamine synthesis of $E$. coli (wild strain) in the presence of $5-\mathrm{CH}_{2} \mathrm{OH}-\mathrm{Pm}$ nor $\mathrm{Th}$ promoted the growth of $E$. coli mutant requiring these amino acids.

\section{Effect of $\gamma$-Aceto-r-mercaptopropyl Acetate (AMA) and Dihydrothiamine}

Dihydrothiamine showes about the same activity for $E$. coli mutant as thiamine. AMA alone is inactive for $26-43$ and $70-17$, but somewhat active in the presence of HCHO (Fig. 6, D). AMA alone however shows only a slight activity for $N$. crassa 18558. According to Matsukawa and Iwazu (22) AMA is a substance to be formed directly prior to the synthesis of dihydrothiamine and in the presence of $5-\mathrm{CH}_{2} \mathrm{OH}-\mathrm{Pm}$ plus formaldehyde it is condensed nonenzymatically to dihydrothiamine. The growth of the E. coli mutant in the presence of HCHO may possibly be due to this condensation. AMA which was expected to show the same order of activity as dihydrothiamine, proved to be inactive so that no evidence could be obtained that AMA occurs in the normal metabolic process of the Th formation.

\section{SUMMARY}

1. From our experiments it is assumed that the main pathway of thiamine synthesis is $\mathrm{Pm}+\mathrm{Th} \longrightarrow$ thiamine.

2. $\mathrm{Pm}$ is related to the pyrimidine of nucleic acid.

3. The pathway, cystine (cysteine) $\longrightarrow$ thiazolidine carboxylic acid $\longrightarrow \mathrm{Th}$, is suggested for the biosynthesis of $\mathrm{Th}$.

\section{REFERENCES}

1. Buchman, E. R., and Richardson, E. M., J. Am. Chem. Soc. 61, 891 (1939).

2. Knight, B. C. J. G., Vitamins and Hormones 3, 125 (1945).

3. Sne1l, E. E., Bacterial Nutrition-Chemical Factors, Chapter VII in Werkman, C. H., and Wilson, P. W., Bacterial Physiology, Academic Press, New York (1951).

4. Knight, B. C. J. G., Biochem. J. 31, 731, 966 (1937).

5. Knight, B. C. J. G., and McIlwain, H., ibid. 32, 1241 (1938).

6. Kaku, B., Nihon-Igaku No. 3406, 13 (1946).

7. Makino, K., Morii, S., and Kaku, B., Vitamins 2, 195 (1949).

8. Matsukawa, T., and Suzuoki, J., ibid. 7, 75 (1954).

9. Hotta, K., Tanaka, S., and Mizuno, K., ibid. 3, 95 (1950).

10. Davis, B. D., J. Am. Chem. Soc. 70, 4267 (1948).

11. Lederberg, J., and Zinder, M., ibid. 70, 4267 (1948).

12. Lederberg, J., Methods in Med. Res. 3, 5 (1950).

13. Lederberg, J., and Lederberg, E. M., J. Bact. 63, 399 (1952).

14. Davis, B. D., Proc. Nat. Acad. Sci. U. S. 35, 1 (1949).

15. Takata, R., and Fukui, S., Vitamins 3, 229 (1950). 
16. Harington, C. R. and Moggaridge, R. C. G., J. Chem. Soc. 422 (1939) ; Biochem. J. 34, 385 (1940).

17. Bonner, J., and Buchman, E. R., Proc. Nat. Acad. Sci. 24, 431 (1938).

18. Doudney, C. O., and Wagner, R. P., ibid. 39, 1043 (1953).

19. Tatum, E. L., and Bell, T. T., Am. J. Botany 33, 15 (1946).

20. Matsukawa, T., and Yurugi, S., Vitamins 3, 164, 243, 296 (1950).

21. Takata, R., and Fukui, S., ibid. 4, 369 (1951).

22. Matsukawa, T., and Iwazu, T., ibid. 8, 183 (1955).

23. Fujita, A., Nose, Y., and Kuratani, K., J. Vitaminol. 1, 1 (1954). 